\title{
STUDIES ON THE EFFECT OF BIOFERTILIZERS ON THE GERMINATION OF ACACIA NILOTICA LINN. SEEDS
}

*P. Kumudha

\section{Introduction}

Forests protect and enrich the soil mantle by reducing soil erosion and nutrient loss and by facilitating nutrient recycling and microbiological activities. They act as 'sink' for atmospheric $\mathrm{CO}_{2}$ and release large amounts of $\mathrm{O}_{2}$. Forests also serve as a unique storehouse of plant and animal genetic resources and contribute significantly to the biological diversity of the country which inturn serves as an insurance against food crisis and as an assurance for health care. The forest zones of India occupy about $22 \%$ of geographical area and recent aerial survey has indicated that only about $12 \%$ is under functional forest area. The satellite data of National Remote Sensing Agency (NRSA) has revealed that India keeps losing its natural forests at the rate of 1.3 million hectares every year.

The forestry sector is an important contributor to the economic and social well being of a country. Today earths green shield is under threat of extinction along with its natural resources. This is due to over exploitation by man. The only solution to overcome this problem is large scale afforestation. A successful afforestation programme is completely depended upon the availability and supplyof high quality seeds of different tree species, since most of them are propagated by seeds.

* Deportment of Botany, Vellalar College for Women, Erode-9, T.N. 
The good quality planting stock material can be produced by applying biofertilizers, biocides and nutrients to the seeds and seedlings at the nursery level. Biofertilizers have attracted greater attention particularly in developing countries like India as a substitute for costly chemical fertilizers. India's production of nitrogen ad phosphate fertilizers is well below their provisional consumption and part of the deficit is met through importation. Biofertilizers can obviate the need of importation of fertilizers and at the same time be cost effective and compatible with ecology.

Biofertilizer or microbial inoculants can be generally defined as preparations containing live or latent cells of efficient strains of nitrogen fixing, phosphate solubilizing or cellulolytic microorganisms used for application of seed, soil or composting areas with the objective of increasing the numbers of such microorganisms and accelerate certain microbial processes to augment the extent of the availability of nutrients in a form which can be easily assimilated by plants. Biofertilizers which improve soil quality are ecofriendly and provide yield increments which greatly benefit farmer with only very small input cost.

Keeping this in view, a study was conducted to find out the effect of biofertilizers on the germination of Acacia nilotica seeds.

\section{Materials and Methods}

Acacio nilolica Linn is an armed tree with thorns. Wood is brown, hard, strong and used for agricultural and many other purposes. It belongs to the family Mimosaceae. Fresh seeds of Acacia nilotica (Karuvelam) were procured from Forest college and Research Institute, TamilNadu Agricultural University (TNAU), Mettupalayam, Coimbatore district and used for pot culture and laboratory experiments.

\section{Pot culture experiments in red loamy soil using biofertilizers singly and in combination}

The pot culture experiments were carried out at Bharathiar University, Coimbatore, using completely Randomized Block Design (RBD) with four replications. The biofertilizers were obtained from the Department of Agricultural Microbiology, Tamil Nadu Agricultural University, Coimbatore.

The pots were filled with $9 \mathrm{~kg}$ of red loamy soil and inoculated with biofertilizers like Rhizobium, phosphobacteria, and vesicular arbuscular mycorrhiza (VAM). The various treatments employed are detailed below. 


$\begin{array}{lll}\mathrm{T}_{1} & \text { - } & \text { Rhizobium @ } 18 \mathrm{~g} / \mathrm{pot} \\ \mathrm{T}_{2} & \text { - } & \text { Phosphobacteria@ } 18 \mathrm{~g} / \mathrm{pot} \\ \mathrm{T}_{3} & \text { - } & \text { VAM@ } 45 \mathrm{~g} / \text { pot } \\ \mathrm{T}_{4} & \text { - } & \text { Rhizobium + phosphobacteria @ } 9+9 \mathrm{~g} / \mathrm{pot} \\ \mathrm{T}_{5} & \text { - } & \text { Rhizobium + VAM@ } 9+22.5 \mathrm{~g} / \mathrm{pot} \\ \mathrm{T}_{6} & \text { - } & \text { Phosphobacteria + VAM@ } 9+22.5 \mathrm{~g} / \mathrm{pot} \\ \mathrm{T}_{7} & \text { - } & \text { Rhizobium + phosphobacteria + VAM@ } 6+6+15 \mathrm{~g} / \mathrm{pot} \\ \mathrm{T}_{8} & \text { - } & \text { Uninoculated with none of the above served as control. }\end{array}$

All the samples both inoculated as well as uninoculated consisted of 50 seeds. They were sown separately in each pot. The recommended nursery management practices were followed for the production of elite seedlings.

Germination percentage was recorded after emergence of plumule (seventh day) for all the four selected tree species. The growth parameters like root length, shoot length, seedling fresh weight and seedling dry weight were recorded after 60,90 and 120 days after sowing (DAS).

Besides this, the seedlings were analysed for the biochemical parameters such as the contents of chlorophyll a, chlorophyll b, total chlorophyll, total soluble carbohydrates, reducing sugars, total free amino acids, total proteins and total free phenolics.

The analysed minerals include nitrogen, phosphorus, potassium, calcium and magnesium. In each replication, measurements were taken for five seedlings and mean was worked out.

Total chlorophyll content was measured by using the method of Arnon (1949), total soluble carbohydrates by the method of Clegg (1956), reducing sugars by the method of Nelson (1944), total free amino acids by the method of Moore ef al (1948), total proteins by the method of Lowry et al (1951) and total free phenolics by the method of Maxon and Rooney (1972) for extraction and Sadasivam and Manickam (1992) for estimation.

The seedlings were oven-dried at $80^{\circ} \mathrm{C}$ for 24 hours and subjected to the analysis of selected minerals. Nitrogen content was calculated by microkjeldahl method (Humphries, 1956), phosphorus content by the method of Jackson (1973), potassium content by flame photometric method (Jackson, 1973). Calcium and magnesium contents were measured by versenate method (Cheng and Bray, 1951). Date obtained were subjected to statistical analysis as per the procedure outlined by Panse and Sukhatme (1967). The results are presented in Tables 1 to 7. 


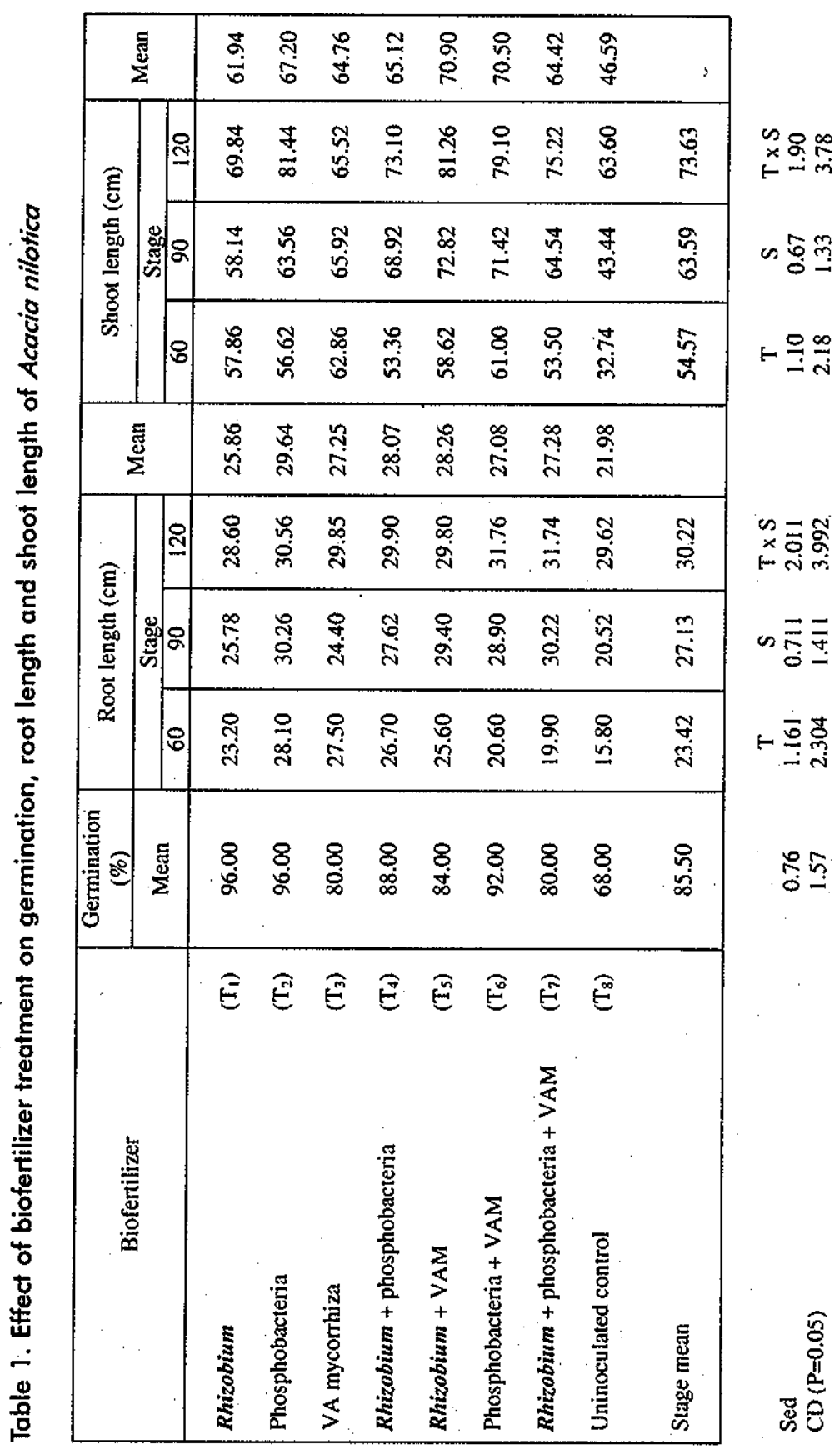




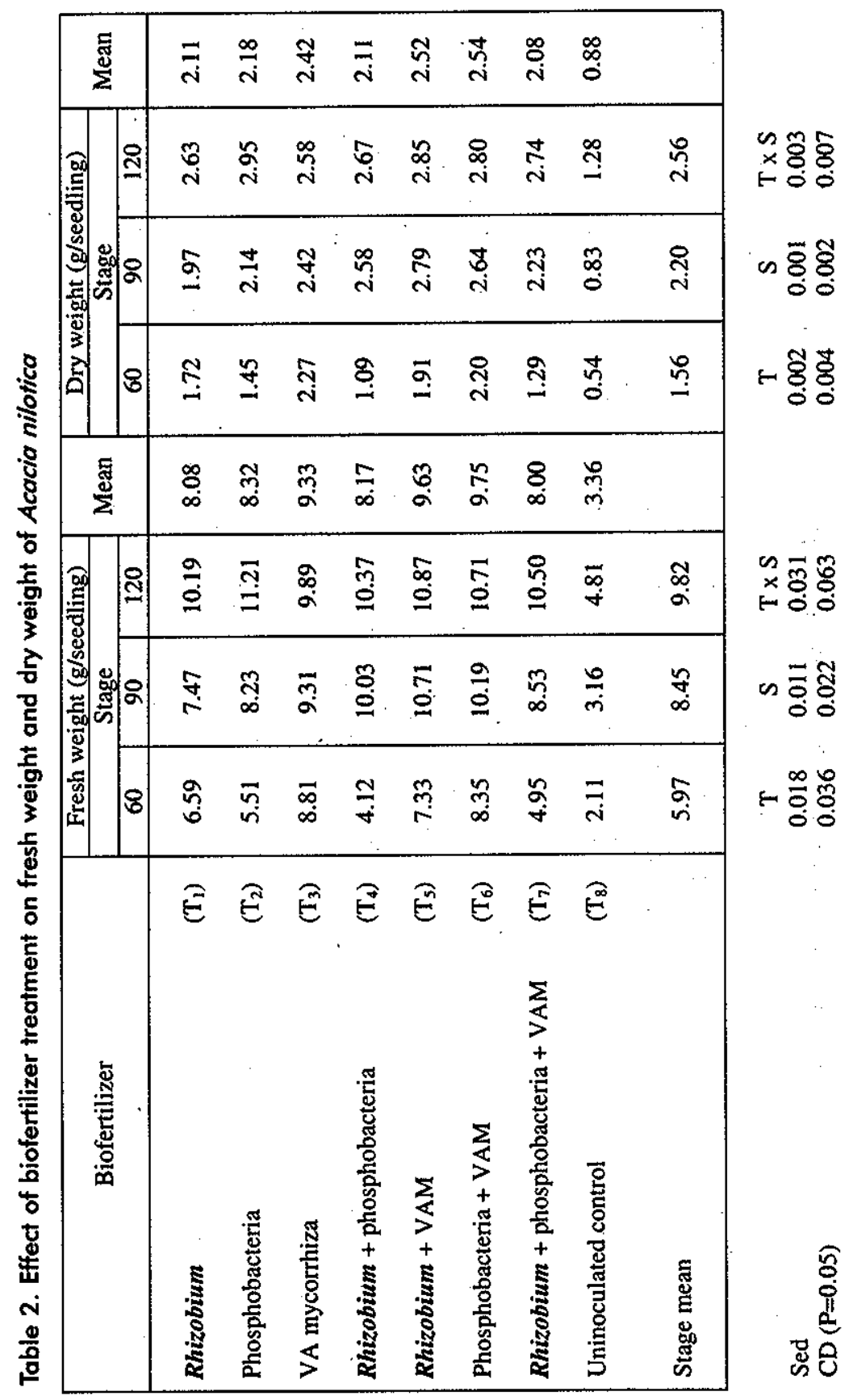




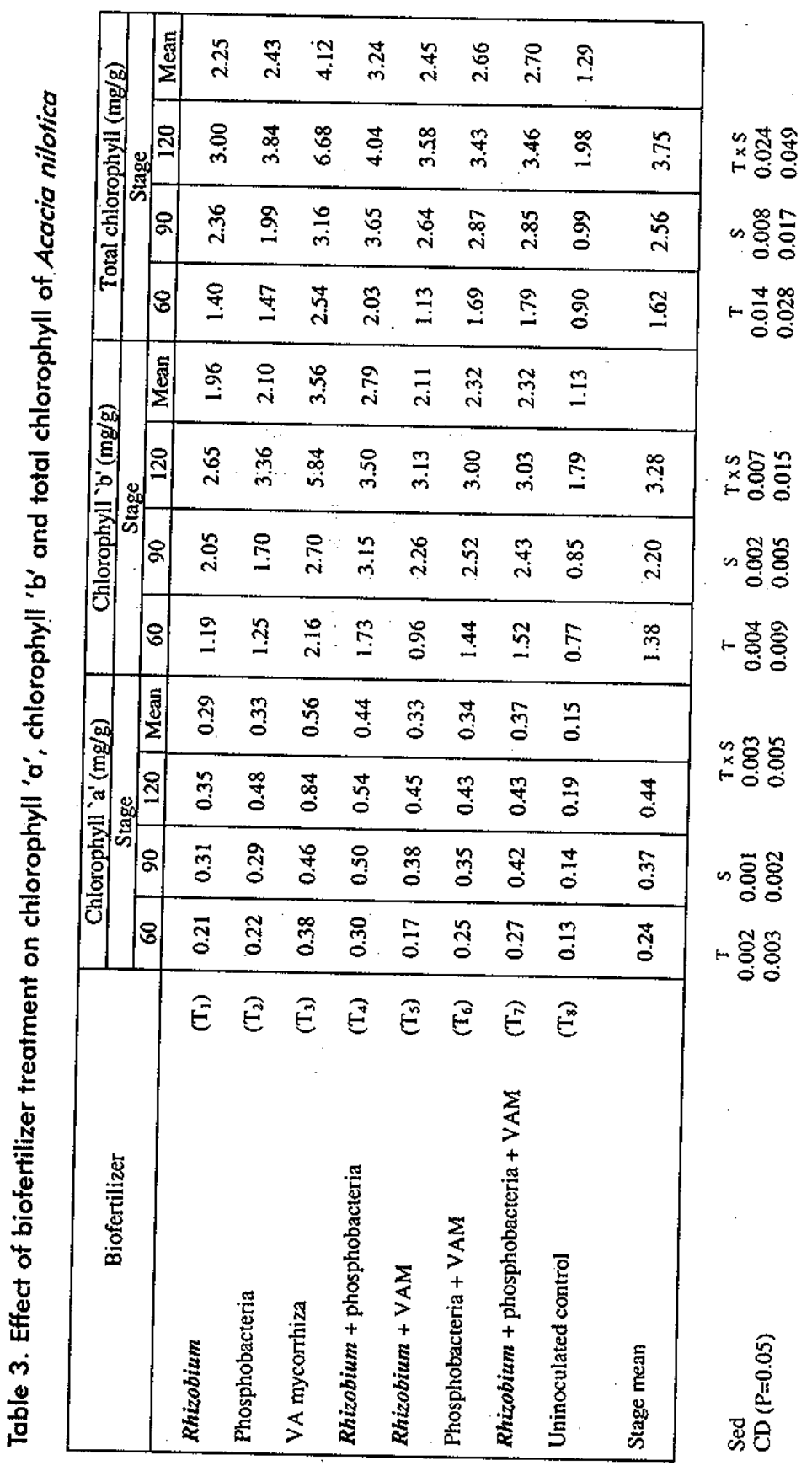




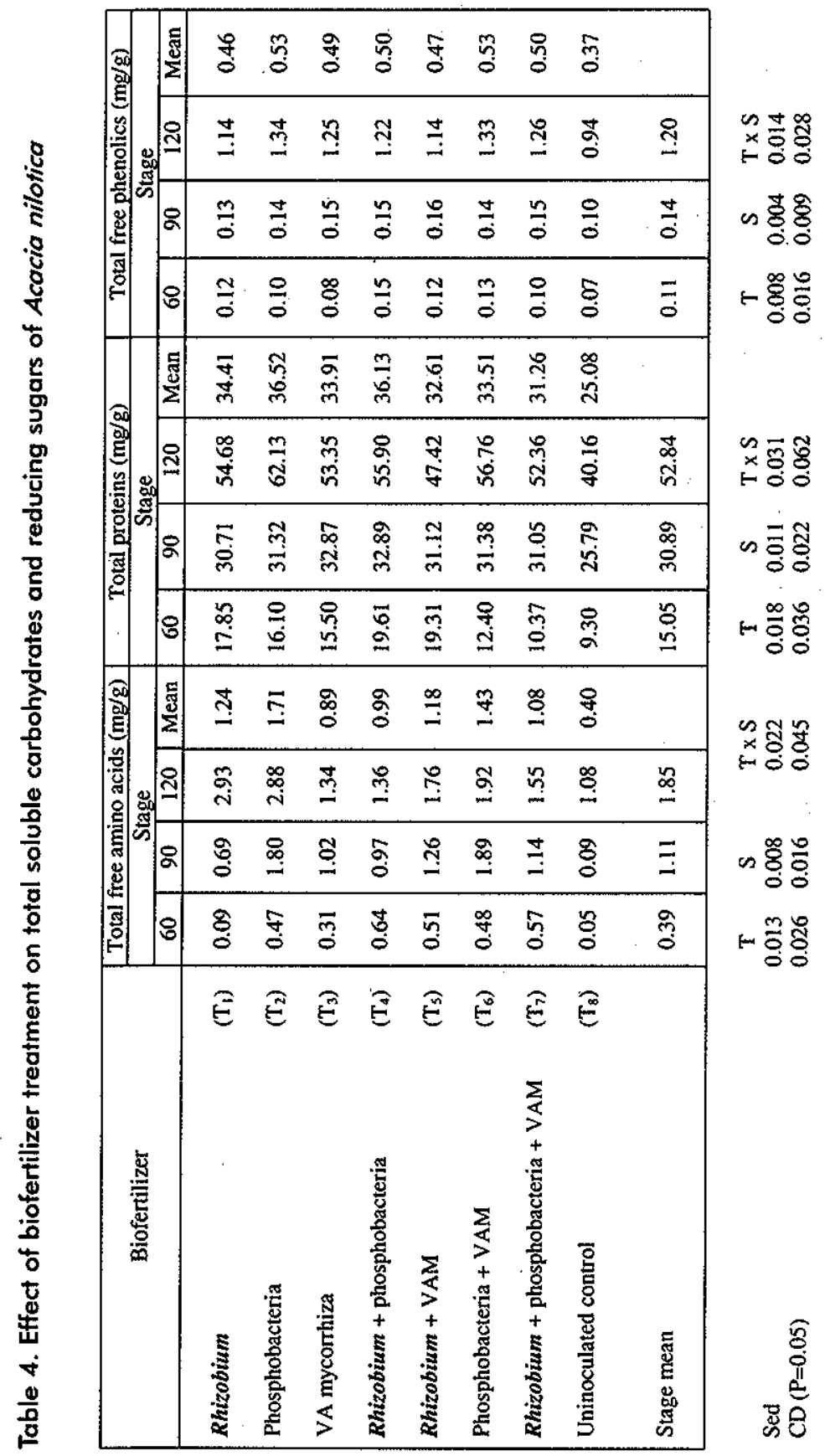




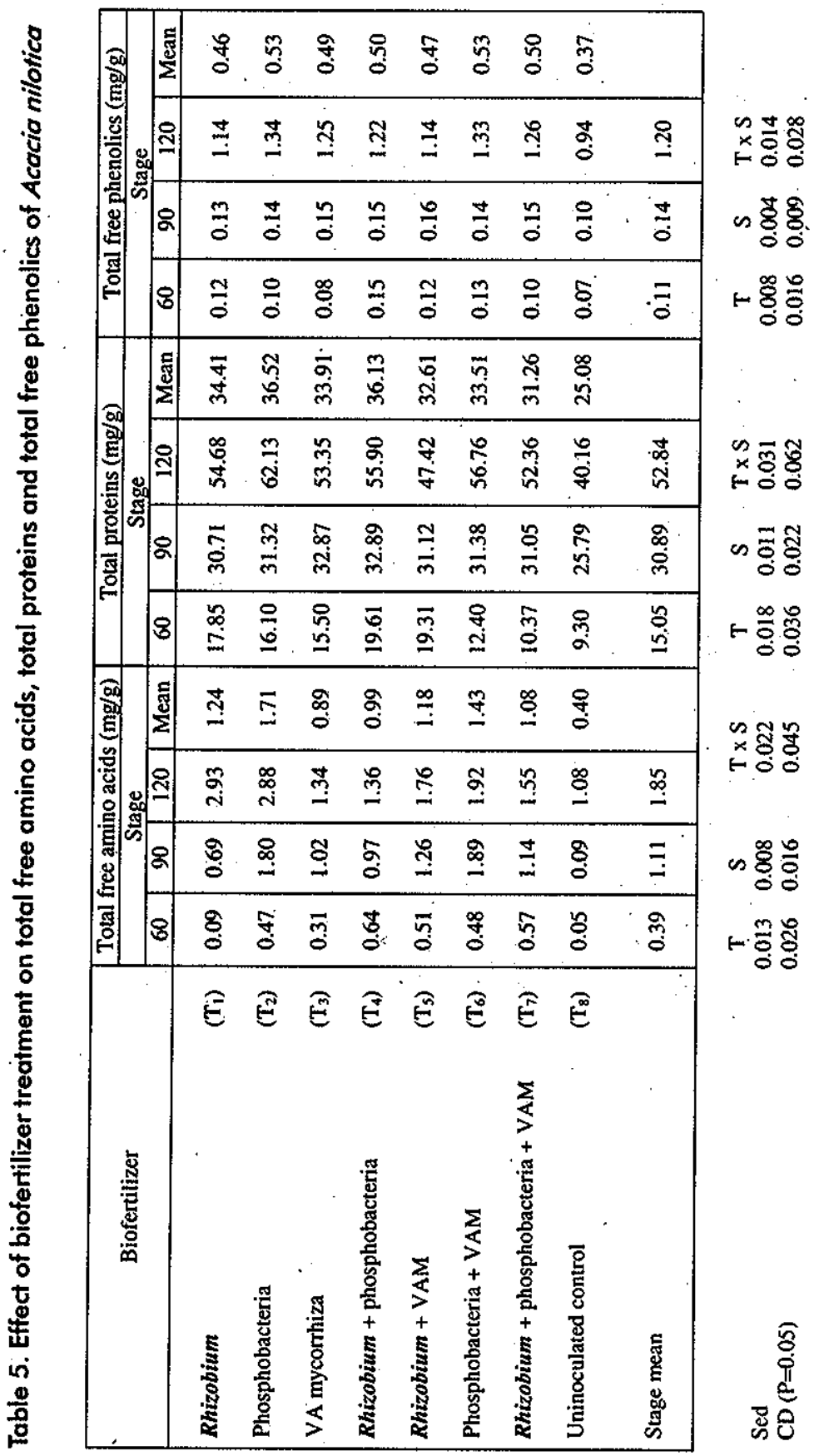




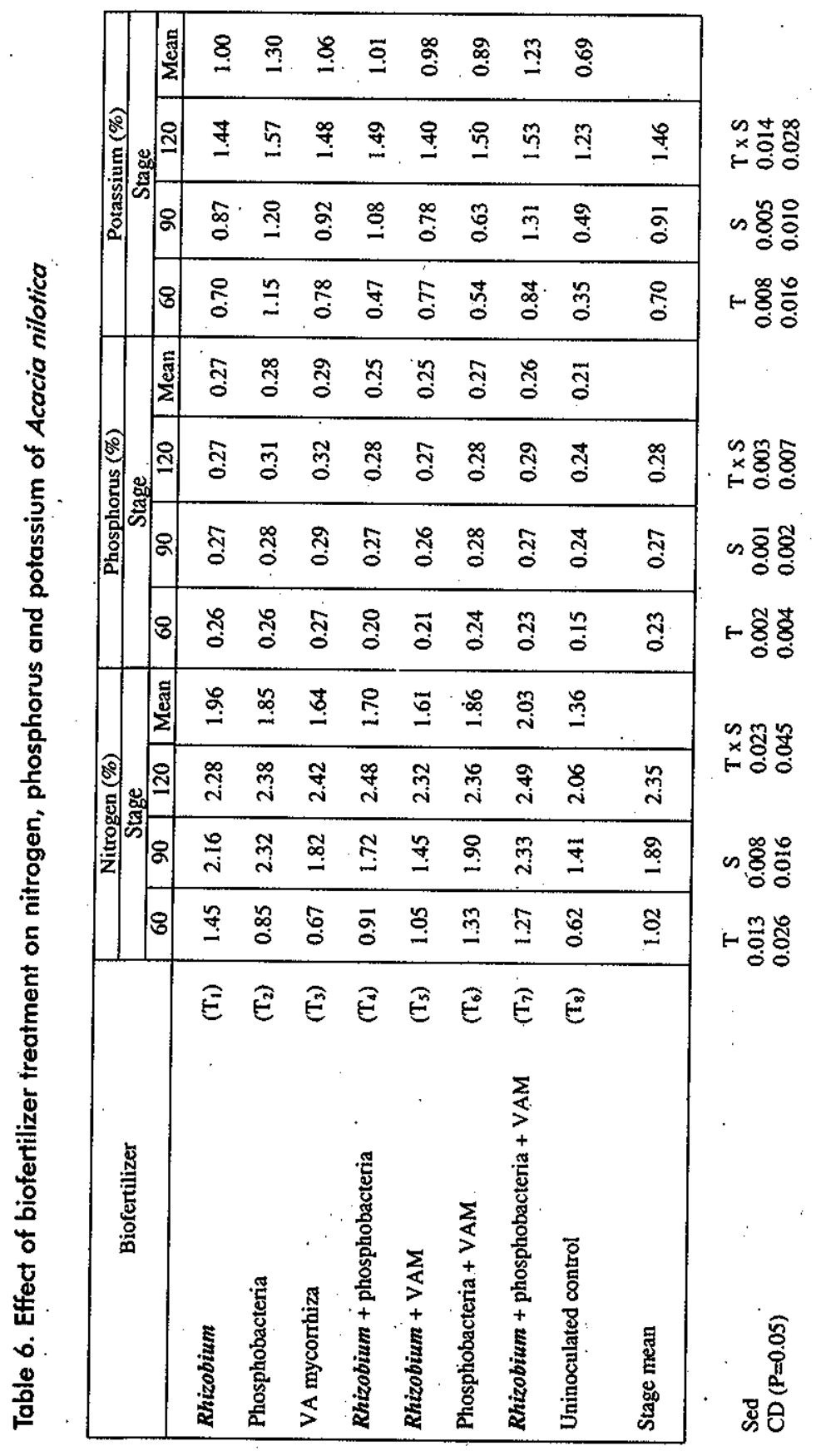




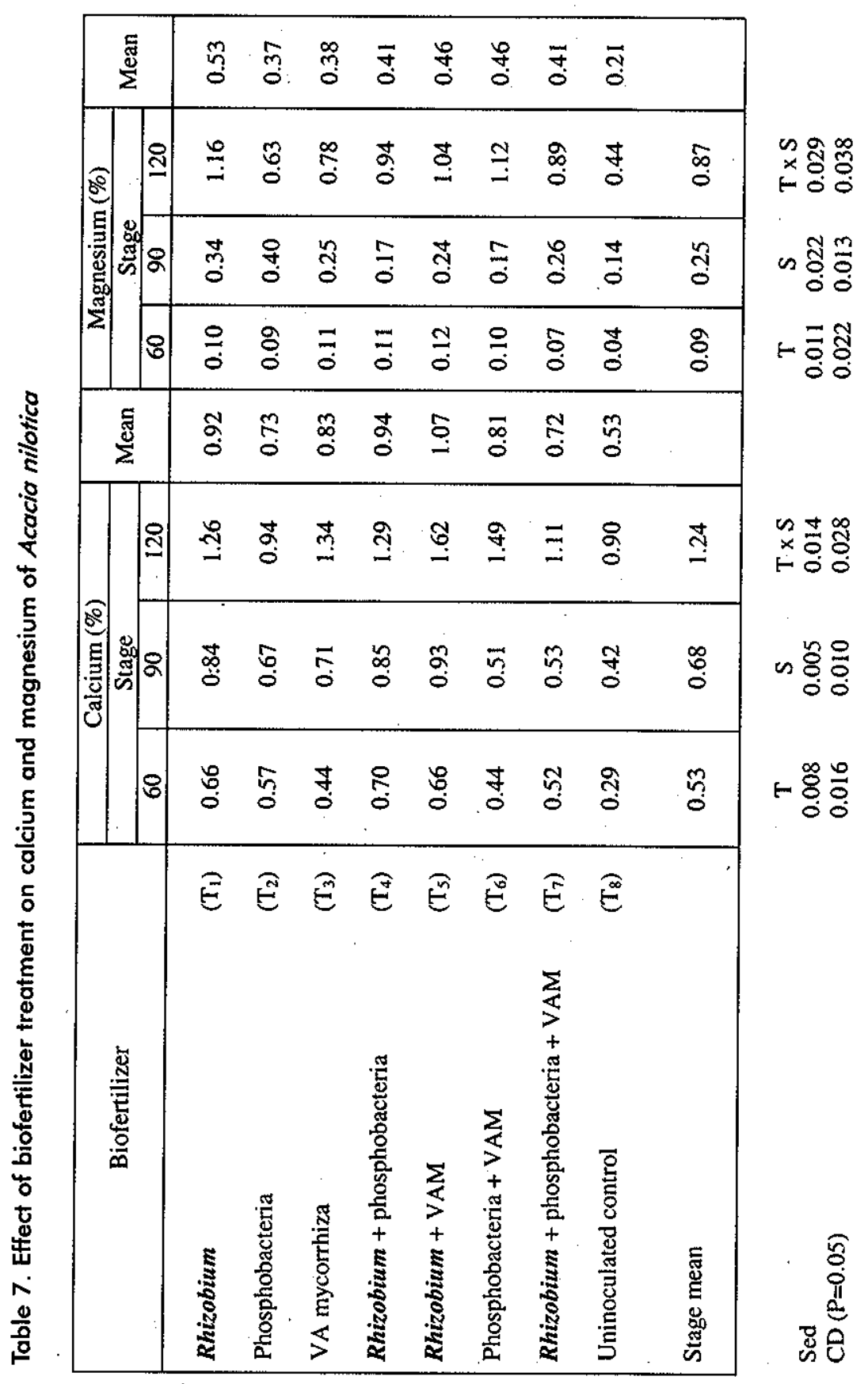




\section{Results and Discussion}

In Acacia nilotica the highest seed germination percentage (96\%) is induced by Rhizobium and phosphobacteria treatments individually. The relative enhancement of seed germination might be attributed to the role of phosphorus solubilizing bacteria known as phosphobacteria in enhancing the availability of phosphorus in the soil (Cooper, 1979) and making it available to the germinating seed with consequent enhancement in the metabolic activity resulting in higher germination.

In Acacia nilotica seedlings, longer roots are produced by phosphobacteria and longer shoots are produced by Rhizobium + VAM. The possible mechanisum by which $\mathrm{P}_{-}$solubilizing microorganisms influence $\mathrm{P}$ availability to plants include solubilize $P$ from insoluble form by the production of organic acids and these organic acids may chelate $P$ and make it more available to plants and by producing cytokinins which stimulate root growth that inturn may permit $P$ absorption from large volume of soil (Barea et al., 1976).

Increase in shoot height in seedlings of Artocarpus integrifolia inoculated with VAM is reported recently (Srivastava et al., 2001). It is suggested that vaM can improve plant growth through increased uptake of $P$ especially in low fertile soils (Gerdemann, 1975). The increase in length of shoot and root due to combined inoculation of biofertilizers is documented in several shola species (Anon, 1978; Rangarajan and Narayanan, 1990; Sekar et al., 1995). The increase in plant growth attributes might be due to increased uptake of nutrients in mycorrhizal associated plants and its synergistic effect with other inoculum (Srinivas, 1987). Phosphobacteria + vaM inoculation have shown the heighest fresh and dry weights in the seedlings studied. The work of Gurumurthy et al., supports this view. Increase in biomass production in seedling may be strongly correlated with accumulation of $\dot{P}$ due to mycorrhizal fungi and phosphobacteria inoculation (Sanders et al., 1975). Total chlorophyll content was very high in the seedlings inoculated with vam in Acacia nilotica.

In our study, the content of total soluble carbohydrates was maximum in Rhizobium + phosphobacteria and the maximum contents of reducing sugars, total free amino acids, total proteins and total free phenolics were noticed in phosphobacteria inoculation. The enhanced biochemical attributes due to single and dual inoculations were supported by the work of several investigators (McArthur and Kowlis, 1993; Sivaprasad and Rai, 1988) in several forest tree species. Higher N content due to triple inoculation (Rhizobium + phosphobacteria + VAM), P \& K content due to single inoculation (vam and phosphobacteria respectively), Ca uptake due to dual inoculation (Rhizobium + vaM) and Mg content due to single inoculation (Rhizobium) were noticed in our present study. 
Various reasons are propounded to explain the increased uptake of $N$ in VAmycorrhizal plants viz., the increased uptake of $N$ due to $N$ fixation which is induced secondarily by increased $\mathrm{P}$ uptake rather than to direct uptake of $\mathrm{N}$ compounds from the soil (Puni and Gupta, 1987) and the increased N uptake also might be due to the reduction of nitrate to nitrite by vau fungi (Theobold and Smith, 1974). The increased $N$ uptake in VA mycorrhizal plants might also be due to the increased $\mathrm{P}$ uptake which in turn might enhance the activity of NAD dependent enzyme, which might contribute to nitrate reductase activity (Trappe and Fogel; 1977).

Punj and Gupta (1987) confirm the role of mycorrhiza in supplying $P$ to the host tree. Sanders ef al (1975) observe that in mycorrhizal plants, incrased $P$. uptake is due to existence and continued growth of extramatrical mycelium into soil extending beyond the phosphate depletion zone around the root and exploiting a greater and less depleted zone. Increased $\mathrm{K}$ uptake due to phosphobacteria inoculation in neem is reported by Kalavathy et ol. (2000). The enhancement in levels of micronutrients due to biofertilizer inoculation in this study might be due to symbiotic effect of biofertilizers with host tree seedlings, which effects an improvement in micronutrient uptake and mineral status (Buwalda et al., 1983).

The results of the present study reveal that almost all the employed biofertilizers (singly and in combination) enhance seed germination, seedling growth and most of the biochemical parameters. Among the biofertilizers, phosphobacteria inoculation is found to be more effective in general and vam inoculation is found to be effective in chlorophyll pigments accumulation. From this study, it is concluded that biofertilizer inoculations will improve the plant growth, biomass and biochemical constituents of the seedlings and thereby help to produce elite seedlings and improve the survival rate of planted seedlings. Production of elite seedlings is a pre requisite for the successful implementation of extensive planting programmes such as afforestation, social forestry and agroforestry.

\section{References}

1. Arnon, D.E. 1949. Copper enzymes in isolated chloroplasts. PI. Physiol. 24: 1-5.

2. Clegg, K.M. 1956. The application of the anthrone reagent to the estimation of starch in cereals. J. Sci. Food Agric. 7: 40-44.

3. Nelson, N. 1944. A photometric adaptation of the somogyi for the determination of glucose. J. Biol. Chem. 153: 375-380. 
4. Moore, S. and W.H. Stein. 1948. Photometric method for use in chromatography of amino acids. J. Biol. Chem. 176: 367-388.

5. Lowry, O.H., N.J. Rosebrough, A.L. Farr and R.J. Randall. 1951. Protein measurement with folin phenol reagent. J. Biol. Chem. 193: 265-275.

6. Sadasivam, S. and A. Manickam. 1992. Biochemical methods for agricultural sciences. Wiley-Eastern Ltd., New Delhi, pp. 187-188.

7. Humphries, E.C. 1956. Mineral components and ash anolysis. In: Modern methods of plant analysis. Eds. K. Paech and M.V. Tracey. Springer-Verlag-Berlin. 1: 468-502.

8. Jackson, M.L. 1973. Soil chemical analysis. Prentice Hall of India (Pot.) Ltd., New Delhi, pp. 461-464.

9. Cheng, K.L. and R.H. Bray. 1951. Determination of calcium and magnesium in soil and plant material. Soil Sci. 12: 449-458.

10. Cooper, R. 1979. Bacterial fertilizers in the Soviet Union. Soil Fert. 22: 327-333.

11. Barea, J.M., Navarro, E. and Montaya, E. 1976. Production of plant growth regulators by rhizosphere phosphate solubilizing bacteria. J. Appl. Bacteriol. 40: 129.131.

12. Srivastova, K.K., V. Mohan and Neelam Verma. 2001. Impact of VAM inoculation on some semi-arid tree species. Indian For. 127: 936-940.

13. Gerdemann, J.W. 1975. Vesicular arbuscular mycorrhizae. In: The development and function of roots (eds) J.G. Torrey and D.T. Clarkson, Academic press, New York. pp. 575-595.

14. Anon, 1978. Tree borne oil seeds. Directorate of non edible oils and soap industry. Bomaby : Khadi and Village Industries Commission, India.

15. Narayanan, R., M. Rangarajan and B. Kandasamy, 1990. Response of a shola plant Rhododendron nilagiricum to endomycorrhizal inoculation. In: Proceeding of the National Conference on Mycorrhizoe. Hissar Agricultural University, Hissar, India. Feb. 14-16, 1990. pp. 11-12.

16. Sekar, I., K. Vanangamudi and K.K. Suresh. 1995. Effect of biofertilizers on the seedling biomass, VAM colonization, enzyme activity and phosphorus uptake in the shola tree species. My Forest 31: 21-26.

17. Srinivas, K. 1987. Studies on the occurrence of VAM fungi and their interactions with some forest tree species. M.Sc. (Ag.) Thesis, Tamil Nadu Agricultural University, Coimbatore, India.

18. Sanders, F.E., B. Mosse and P.B. Tinker. 1975. Endomycorrhizoe, Academic Press, London, 437-446.

19. McArthur, D.A.J. and N.R. Kowlis. 1993. Influence of vesicular arbuscular mycorrhizal fungi on the response of potato to phosphorus deficiency. PI. Physiol. 101: 147-160.

20. Sivaprasad, P. and P.V. Rai. 1988. Mechanism of enhanced nodulation in vesicular arbuscular mycorrhiza VAM in pigeonpea (Cajanus cajan (L.) Mill sp.). Agric. Res. J. 25: 99-102. 
21. Puni, V. and R.P. Gupta. 1987. VAM and Rhizobium as biological fertilizers for Leucaena leucocephola. Acta Microbiol. Pol. 37: 327-336.

22. Theobold, W.F. and W.H. Smith. 1974. Nitrate production in two forest soils and nitrate reduction in pine. Soil Sci. Soc. Am. Proc. 38: 668-672.

23. Trappe, J.M. and R.D. Fogel. 1977. Ecosystem function of mycorthizae in the below ground ecosystem. A synthesis of plant associated process. (Ed.) J.K. Marshall, Colarado State University, Range, Sci. Dept. Sci. Senvices, No. 26, Fort Collins.

24. Kalavathi, B.P., P. Santhanakrishnan and M.P. Divya. 2000. Effect of VA-mycorrhizal fungus and phosphorus solubilising bacterium in neem. Indian For. 126: 67-70.

25. Buwalda, J.G., D.P. Stribley and P.B Tinker. 1983. Increased uptake of anions by plants with VAM. PI. Soil. 71: 463-467. 